\title{
Cromatografia gasosa bidimensional abrangente aplicada à análise qualitativa dos componentes majoritários do bio-óleo da pirólise de bagaço de laranja
}

\author{
Maria Silvana Aranda Moraes ${ }^{1}$, Janaína Heberle Bortoluzzi², \\ Marcelo Vieira Migliorini ${ }^{1}$, Cláudia Alcaraz Zini ${ }^{1}$, Elina Bastos Caramão ${ }^{\text {* }}$ \\ ${ }^{1}$ Instituto de Química, Universidade Federal do Rio Grande do Sul - UFRGS, \\ Av. Bento Gonçalves, 9500, Cep 91501-970, Porto Alegre, RS, Brasil \\ ${ }^{2}$ Instituto de Química e Biotecnologia, Universidade Federal de Alagoas - UFAL, \\ Av. Lourival de Melo Mota, s/n, Cidade Universitária, Cep 57072970, Maceió, AL, Brasil \\ e-mail:elina@ufrgs.br
}

Resumo

O Brasil ocupa posição de destaque no cenário internacional como produtor de laranja e também na utilização adequada do bagaço, que é um subproduto do processo de produção de suco. O uso racional deste resíduo é de extrema importância, tanto pelos aspectos ambientais como econômicos. O bio-óleo proveniente da pirólise rápida de bagaço de laranja apresenta-se como uma alternativa de emprego deste resíduo que pode agregar valor a este material, produzindo energia ou matéria-prima para a indústria química. Neste trabalho foram tentativamente identificados 167 compostos, sendo 26 destes encontrados em concentração superior a $1 \%$, através de cromatografia gasosa bidimensional abrangente com detector de ionização em chama (GC×GC-FID) e também com detector espectrométrico de massas por tempo de voo (GC×GC/TOFMS). Além disso, a otimização de alguns parâmetros cromatográficos foi apresentada. A seletividade superior da GC $\times$ GC/TOFMS relativamente à cromatografia monodimensional é ilustrada pela separação na segunda dimensão de compostos que coeluem na primeira dimensão, bem como através da ferramenta de deconvolução espectral. Essa permite a separação de compostos por diferenças nos respectivos espectros de massa nos casos em que a separação cromatográfica não foi possível.

Palavras-chave

Pirólise; laranja; cromatografia gasosa bidimensional abrangente com detector espectrométrico de massas por tempo de voo; GC×GC-FID; GC×GC/TOFMS.

\section{Comprehensive two-dimensional gas chromatography applied to the qualitative analysis of major compounds of bio-oil from pyrolysis of orange pulp}

Abstract

Brazil occupies a prominent position on the international scene as a producer of orange and in the appropriate use of bagasse, which is a byproduct of juice production process. The rational use of this waste material is of great importance, as by environmental or economical aspects. The bio-oil from fast 
pyrolysis of orange pulp is an alternative use of this residue, which can agregate value to this material, producing energy and chemical raw materials. In this study, 167 compounds were tentatively identified by comprehensive two-dimensional gas chromatography with flame ionization detector (GC $\times$ GC-FID) and mass spectrometry detector for time of flight (GC $\times$ GC/TOFMS), twenty six of these are found in concentrations above $1 \%$. In addition, the optimization of some chromatographic parameters was presented. The higher selectivity of GC $\times \mathrm{GC} / \mathrm{TOFMS}$ for the one-dimensional chromatography is illustrated by the separation in the second dimension of co-eluting compounds in the first dimension, as well as by spectral deconvolution tool. This allows the separation of compounds by differences in their mass spectra, in the cases where the chromatographic separation was not possible.

Keywords

Pyrolysis; orange; two-dimensional gas chromatography; GC×GC/FID; GC×GC/TOFMS.

\section{Introdução}

Biomassa pode ser definida como toda matéria orgânica, seja de origem animal, vegetal ou de microorganismos, suscetível de ser transformada em energia (bioenergia) ${ }^{[1]}$. O emprego de biomassa proveniente de resíduos orgânicos agroindustriais como matéria-prima para a produção de energia é uma alternativa conveniente para este tipo de subproduto ${ }^{[2]}$.

O Brasil possui uma das maiores diversidades de biomassa do planeta e, dentre estes materiais, podem ser citados aqueles que se apresentam como fontes promissoras para utilização em processos de pirólise, tais como sementes, frutas, grãos, folhas e cascas $^{[3]}$. Resíduos como palha de cana-de-açúcar, casca de arroz, caroço de pêssego, semente de uva, capim elefante, fibra de coco, nó de pinho, serragem de eucalipto e bagaço de laranja são exemplos de biomassa proveniente da atividade agroindustrial e que demanda um destino econômica e ambientalmente correto, para que não se transformem em poluentes ambientais ou em desperdício de recursos por serem subutilizados ${ }^{[4-8]}$.

A composição química da biomassa residual pode apresentar variações em função da variedade da planta que deu origem ao resíduo, da localização geográfica da plantação original, do tipo de cultivo, entre outros parâmetros. Esses materiais consistem em fonte de energia alternativa renovável (bioenergia), que vem a complementar a matriz energética atual, além de possibilitar a geração de produtos que podem apresentar maior valor agregado para a sociedade. A grande biodiversidade do Brasil torna-o um país de grande potencial para produção de bioenergia e também de outros materiais mais nobres do que a biomassa de partida ${ }^{[1]}$.

O Brasil destaca-se no cenário mundial como grande produtor de laranja, sendo que somente no ano de 2009 produziu aproximadamente 18 milhões de $t$, que são utilizadas basicamente para a produção de suco. O bagaço da laranja é um resíduo de processo e pode ser empregado para produção de pectinases e para alimentação de gado ${ }^{[31]}$. Entretanto, o mau gerenciamento de sua disposição final pode acarretar em dano ambiental. A geração de bio-óleo de laranja através de pirólise apresenta-se como mais uma alternativa de aplicação para o bagaço de laranja ${ }^{[3]}$.

A pirólise é um dos processos de transformar biomassa para fins energéticos e para produção de produtos voltados à Química Fina. Ela pode ser definida como um complexo processo físico-químico no qual ocorre a decomposição térmica de uma determinada matéria-prima 
(compostos orgânicos da biomassa), em atmosfera não oxidante, dando lugar à formação de subprodutos como: resíduo sólido rico em carbono (carvão), cinzas (originadas da matéria-prima que não se volatiliza), uma fração volátil composta de gases e, ainda, vapores orgânicos condensáveis que originam um líquido pirolenhoso chamado de bio-óleo ${ }^{[4,9-11]}$. O bio-óleo é um líquido viscoso de composição complexa, parcialmente solúvel em água, de cor marrom-escura e um desagradável odor de fumaça. É composto de moléculas de tamanhos diferentes, resultantes principalmente de despolimerização e fragmentação dos três principais blocos que constituem a biomassa: celulose, hemicelulose e lignina ${ }^{[12]}$. Possui um alto teor de água em sua composição química, sendo geralmente rico em grupos fenólicos ${ }^{[4,13-15]}$. A composição da biomassa apresenta um papel fundamental na distribuição dos produtos da pirólise, sendo que o rendimento dos mesmos é também uma função das variáveis de processo $^{[16]}$.

A pirólise pode ser lenta, rápida, ultrarrápida, catalítica e à vácuo. Em cada uma destas se podem empregar reatores de leito fixo ou de leito fluidizado. Alguns parâmetros podem ser otimizados no processo como, por exemplo, tempo de permanência da biomassa no reator, taxa de aquecimento do mesmo, etc. ${ }^{[17,18]}$. A pirólise rápida é definida como um processo que acontece a altas temperaturas ( 450 a $700{ }^{\circ} \mathrm{C}$ ), onde a biomassa é rapidamente aquecida sob atmosfera inerte (por exemplo, na presença de nitrogênio). O objetivo deste tipo de pirólise é produzir grandes quantidades de produto líquido (bio-óleo) através da condensação de vapores orgânicos e obter menor quantidade do produto sólido rico em carbono (carvão), bem como de cinzas e compostos voláteis ${ }^{[19]}$. O processo de pirólise é aplicado às mais diversas áreas: amostras biológicas, materiais poliméricos sintéticos, amostras geoquímicas, alimentos e produtos relacionados à agricultura ou provenientes de madeira, amostras ambientais e da área forense, entre outras ${ }^{[10,20-23]}$.

Diversas técnicas têm sido empregadas para a caracterização de bio-óleos. A cromatografia gasosa monodimensional (1D-GC, do inglês one dimensional gas chromatography) tem sido a técnica analítica escolhida para a separação de misturas complexas, sendo, portanto, adequada para a análise de bio-óleos ${ }^{[24]}$. A cromatografia gasosa bidimensional abrangente $(\mathrm{GC} \times \mathrm{GC}$, do inglês comprehensive two-dimensional gas chromatography), conhecida desde a década de 90, é uma ferramenta analítica ainda mais poderosa, diferenciando-se da cromatografia monodimensional pela utilização sequencial de duas colunas cromatográficas (a segunda coluna mais curta, do tipo empregado em cromatografia rápida), ligadas por um dispositivo chamado modulador. Nesta técnica, o efluente da primeira dimensão é sequencialmente introduzido na segunda, depois de ter passado por um processo de amostragem e compressão, no modulador, sendo posteriormente liberado para a segunda dimensão. A GC $\times$ GC oferece um significativo aumento de capacidade de pico, seletividade e sensibilidade, além de favorecer a ocorrência de estruturação na distribuição dos picos cromatográficos no espaço de separação, de acordo com a natureza da fase estacionária e dos compostos em análise ${ }^{[25-28]}$. Essas características tornam a técnica extremamente útil para análise de amostras complexas, cuja investigação por 1D-GC é limitada, como no caso das separações de constituintes de bio-óleos. Amostras desse tipo contêm um número elevado de compostos que apresentam diversos isômeros e estão divididos em diferentes classes químicas.

A literatura científica apresenta aplicações da GC×GC aos mais diversos tipos de amostras: petroquímicas, forenses, matrizes 
ambientais, perfumes, óleos essenciais, etc. ${ }^{[29,30]}$. Recentemente, a composição de bio-óleos de diferentes biomassas foi investigada através GC $\times$ GC, utilizando-se detector de ionização em chama (FID -flame ionization detector) e detector espectrométrico de massas por tempo de voo (TOFMS - time of flight mass spectrometer), contudo, não existe relato de estudo do bio-óleo do bagaço de laranja através de GC×GC.

O objetivo deste trabalho é demonstrar a eficiência superior da GC×GC/TOFMS para separação de misturas complexas através da aplicação da mesma à caracterização qualitativa de bio-óleo de bagaço de laranja. Para isto, foi feita a otimização de alguns parâmetros cromatográficos e são apresentados exemplos que evidenciam a maior seletividade da técnica através de separação de compostos na segunda dimensão, bem como do uso de deconvolução espectral para analitos que não foram separados cromatograficamente.

\section{Experimental}

\subsection{Solventes e reagentes}

Foram empregados acetona e diclorometano, grau analítico ou equivalente (Merck, Darmstadt, Alemanha). Sulfato de sódio anidro também foi adquirido da Merck. Os gases utilizados para as análises cromatográficas foram hélio, hidrogênio, ar sintético e nitrogênio, sendo o nitrogênio empregado para a evaporação das amostras. A pureza desses gases é superior a 99,999\%. Todos os gases e também o nitrogênio líquido foram adquiridos da Linde Gases (Canoas, RS, Brasil).

\subsection{Pirólise}

Os experimentos de pirólise foram conduzidos até uma temperatura de $500{ }^{\circ} \mathrm{C}$, em um reator de leito fixo, em atmosfera inerte, con- forme descrito em Martins e colaboradores ${ }^{[32,33]}$. O bio-óleo obtido foi seco com sulfato de sódio anidro e posteriormente analisado cromatograficamente.

\subsection{Cromatografia gasosa bidimensional abrangente}

As análises foram realizadas em dois cromatógrafos Agilent $6890 \mathrm{~N}$ (Agilent Technologies, Palo Alto, CA, EUA) equipados com amostrador automático Combi PAL (CTC Analytics AG, Zwingen, Suíça), e detectores de ionização em chama (FID) e de espectrometria de massas por tempo de voo (TOFMS). Os cromatógrafos também possuem forno secundário e modulador térmico de dois estágios com quatro jatos de nitrogênio (dois jatos quentes e dois frios, que são resfriados por vapor de nitrogênio resfriado com nitrogênio líquido, LECO, St. Joseph, MI, EUA). As temperaturas do injetor e detector foram 280 e $320^{\circ} \mathrm{C}$, respectivamente, e a frequência de aquisição de dados foi $100 \mathrm{~Hz}$ para ambos os detectores. A razão do divisor de fluxo foi de 1:10 e o fluxo de hidrogênio (gás de arraste) foi de $1 \mathrm{~mL} / \mathrm{min}$ para o GC×GC-FID.

O conjunto de colunas capilares empregado consistiu em uma coluna contendo a fase estacionária 5\% fenil 95\% polidimetilsiloxano, DB-5 de $(30 \mathrm{~m} \times 0,25 \mathrm{~mm} \times 0,25 \mu \mathrm{m})$ na primeira dimensão $\left({ }^{1} \mathrm{D}\right)$ e uma fase estacionária de $50 \%$ fenil $50 \%$ metil polisiloxano, DB- $17 \mathrm{~ms}$ $(1,3 \mathrm{~m} \times 0,25 \mathrm{~mm} \times 0,25 \mu \mathrm{m})$ na segunda dimensão $\left({ }^{2} \mathrm{D}\right)$, ambas adquiridas da Agilent Technologies - J\&W Scientific (Palo Alto, CA, EUA). A escolha desse conjunto teve por base o trabalho de Marsman e colabores ${ }^{[34]}$.

As condições de análise por GC×GC-FID foram otimizadas, ajustando-se os seguintes parâmetros: comprimento da coluna da segunda dimensão, programação de temperatura para 
a coluna da primeira dimensão, período de modulação, diferença de temperatura entre as duas dimensões, temperatura do modulador, fluxo de gás de arraste e período de duração do pulso quente. Em uma segunda etapa, quando do uso do GC×GC/TOFMS, empregou-se injeção sem divisão de fluxo, temperatura da linha de transferência em $200{ }^{\circ} \mathrm{C}$ (indicação do fabricante), fluxo de gás de arraste (hélio) de $0,7 \mathrm{~mL} / \mathrm{min}$ e o corte de solvente ocorreu a 4,5 minutos. O intervalo de massas de íons adquiridos foi de 35 a 450 Daltons, a energia de ionização de $70 \mathrm{eV}$ e a voltagem do detector foi de $1400 \mathrm{~V}$. O processamento dos dados foi realizado através do software ChromaTOF versão 3.32 .

\section{Resultados}

\subsection{Análise por cromatografia gasosa bidimensional abrangente}

Empregando-se o sistema GC $\times$ GC-FID foram avaliados os seguintes parâmetros: programação de temperatura do forno primário, diferença de temperatura entre os fornos primário e secundário $(\Delta \mathrm{T})$, período de modulação $\left(P_{M}\right)$, temperatura do modulador e duração do jato quente. As três programações de aquecimento do forno primário estão apresentadas na Tabela 1.
A separação cromatográfica mostrou-se superior quando a programação de temperatura número 2 foi empregada, sendo, portanto, escolhida para o desenvolvimento do restante deste trabalho.

$\mathrm{Na}$ sequência, a diferença de temperatura entre os dois fornos $(\Delta \mathrm{T})$ foi avaliada para os seguintes valores: 10,20 e $30{ }^{\circ} \mathrm{C}$. Os diversos períodos de modulação testados $(5,6,8,9$, 10 segundos) foram experimentados com cada um dos $\Delta \mathrm{T}$ mencionados. A melhor condição de análise, em termos de separação cromatográfica, aproveitamento do espaço de separação e minimização de picos fora de ciclo ocorreu quando o $P_{M}$ foi 9 segundos e o $\Delta \mathrm{T}$ de $20^{\circ} \mathrm{C}$. Para um $P_{M}$ de 9 segundos verificou-se de 3 a 4 modulações por pico para os 30 compostos majoritários do cromatograma, o que confirma as constatações reportadas na literatura para o número mínimo de modulações por pico cromatográfico para análise qualitativa ${ }^{[35]}$.

A Figura 1 apresenta o diagrama de cores obtido por GC $\times$ GC-FID para o bio-óleo do bagaço de laranja, quando o $P_{M}$ foi de 6 segundos. Observa-se a ocorrência de pico fora de ciclo, com prejuízo da distribuição estruturada dos compostos no espaço de separação. Além disso, os picos apresentaram cauda na ${ }^{2} \mathrm{D}$ e houve coeluição de alguns compostos com a sangria da coluna cromatográfica. Os mesmos fenômenos

Tabela 1 Programações do aquecimento do forno primário usadas na separação do bio-óleo de laranja em um GC×GC-FID.

\begin{tabular}{|c|c|c|c|}
\hline Parâmetro & Programação 1 & Programação 2 & Programação 3 \\
\hline Temperatura inicial & $40^{\circ} \mathrm{C}$ & $40^{\circ} \mathrm{C}$ & $40^{\circ} \mathrm{C}$ \\
\hline Tempo inicial & 5 minutos & 5 minutos & 5 minutos \\
\hline Taxa de aquecimento & $5^{\circ} \mathrm{C} / \mathrm{min}$ & $3^{\circ} \mathrm{C} / \mathrm{min}$ & $3{ }^{\circ} \mathrm{C} / \mathrm{min}$ \\
\hline Temperatura final & $280^{\circ} \mathrm{C}$ & $180^{\circ} \mathrm{C}$ & $150^{\circ} \mathrm{C}$ \\
\hline Tempo final & 10 minutos & 0 minuto & 1 minuto \\
\hline Tempo total de análise & 63 minutos & 51,7 minutos & 42,7 minutos \\
\hline
\end{tabular}




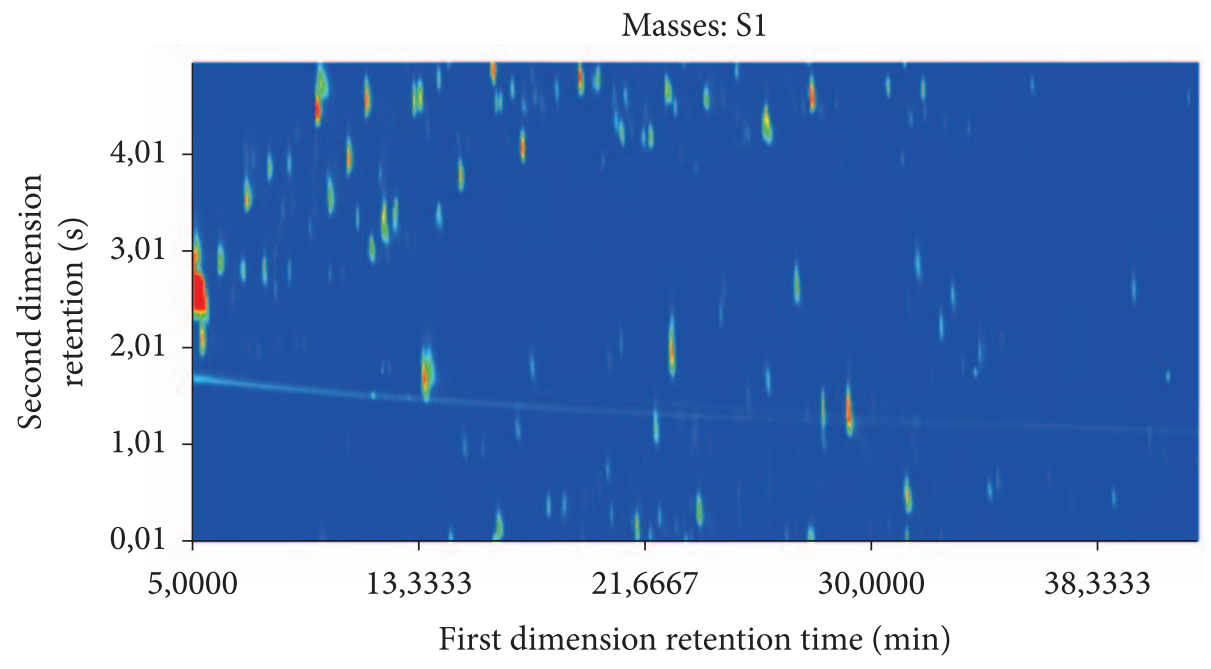

Figura 1 Diagrama de cores para o bio-óleo de bagaço de laranja analisado por cromatografia gasosa bidimensional abrangente. Temperatura do modulador $=35^{\circ} \mathrm{C} ; \Delta \mathrm{T}=20^{\circ} \mathrm{C} ; \mathrm{P}_{\mathrm{M}}=6$ segundos; duração do pulso quente $=60 \%$. Demais condições para a análise por GC $\times$ GC-FID, conforme Parte experimental e programação de temperatura número 2 da Tabela 1.

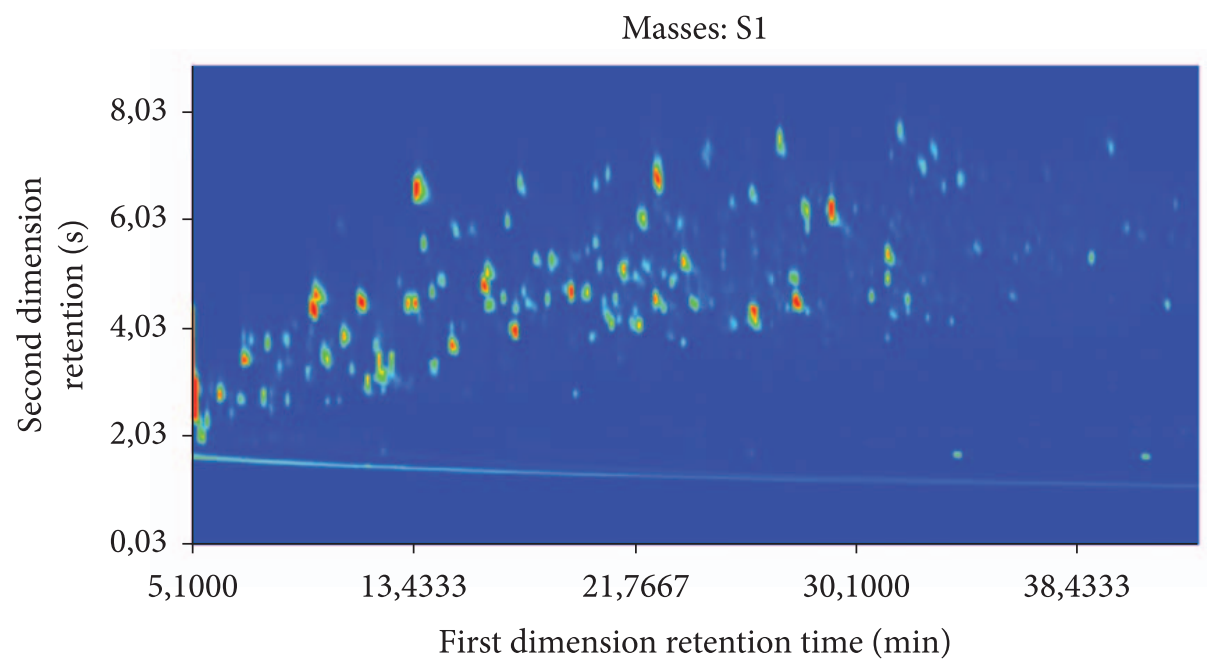

Figura 2 Diagrama de cores para o bio-óleo de bagaço de laranja analisado por cromatografia gasosa bidimensional abrangente com detector de ionização em chama (GC GC-FID). Condições idênticas às da Figura 1, à exceção do $P_{M^{\prime}}$ que foi de 9 segundos.

ocorreram quando foi utilizado o $P_{M}$ de 5 segundos. Os períodos de modulação de 8 e 9 segundos apresentaram os melhores resultados em termos de estruturação cromatográfica e minimização da ocorrência de picos fora de ciclo. Nesse caso não ocorreu coeluição entre os analitos e a sangria da coluna, o que facilita a identificação dos compostos. Não houve diferença significa- tiva nos resultados quando os vários $\Delta \mathrm{T}$ foram empregados, tendo-se escolhido $20{ }^{\circ} \mathrm{C}$ para o restante das análises.

O percentual do tempo de duração do jato quente foi de $20,40,45,60$ e $80 \%$ (este é o percentual de tempo em que o jato quente fica acionado durante o período de modulação, sendo o restante do tempo utilizado para o jato frio). Os 
resultados obtidos nas várias condições testadas foram semelhantes, tendo sido definido $60 \%$ para a duração do jato quente.

Os diagramas de cores foram também avaliados de acordo com diferentes temperaturas para o modulador $\left(15,20,25,30,35,40\right.$ e $\left.50{ }^{\circ} \mathrm{C}\right)$, contudo também neste caso não foram observadas diferenças significativas nos resultados. Foi escolhida a temperatura de $15^{\circ} \mathrm{C}$, que é um valor usual para operação do modulador. A Figura 2

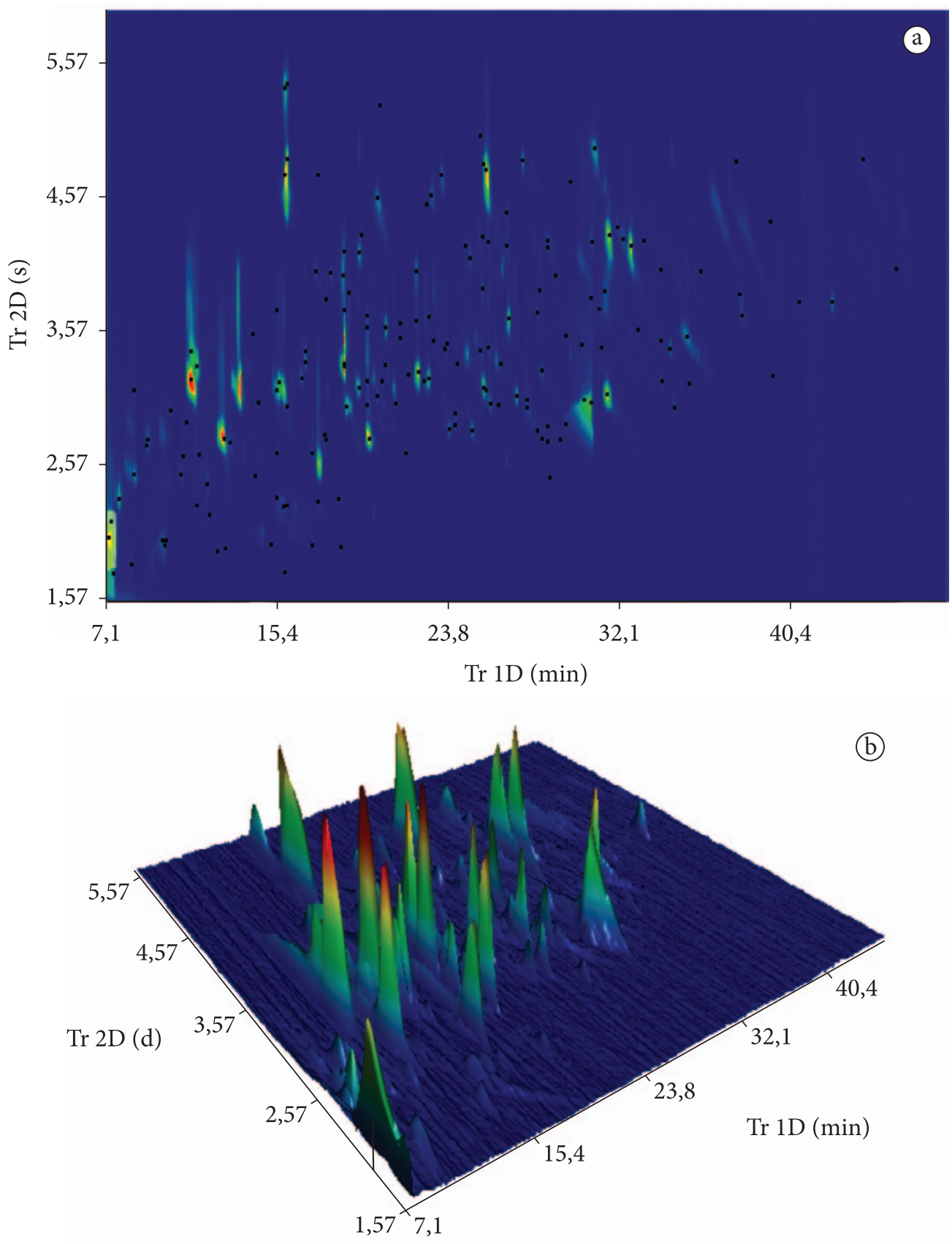

Figura 3 Diagramas de cores obtidos para a análise do bio-óleo de bagaço de laranja analisado por cromatografia gasosa bidimensional abrangente com detector de espectrometria de massas por tempo de voo (GC $\times G C / T O F M S)$. a) Diagrama bidimensional e; b) Diagrama tridimensional de cores. Condições cromatográficas descritas no texto. 
mostra um diagrama de cores resultante das melhores condições cromatográficas.

Algumas condições de operação do $\mathrm{GC} \times \mathrm{GC} / \mathrm{TOFMS}$ que diferem daquelas do GC $\times$ GC-FID como, por exemplo, os $21 \mathrm{~cm}$ de coluna da segunda dimensão na linha de transferência e a presença de alto vácuo no setor do detector, podem requerer alterações nas condições operacionais para que se tenha eficiência cromatográfica semelhante àquela obtida anteriormente. Neste caso foram feitas as seguintes modificações: período de modulação de 6 segundos, diferença de temperatura entre os fornos de $15{ }^{\circ} \mathrm{C}$, temperatura do modulador de $30{ }^{\circ} \mathrm{C}$ e duração do pulso quente de $50 \%$.

A Figura 3 apresenta o diagrama de cores e o diagrama tridimensional para a análise otimizada do bio-óleo de laranja com o sistema

Tabela 2 Compostos majoritários (acima de 1\%) tentativamente identificados no bio-óleo de bagaço de laranja.

\begin{tabular}{|c|c|c|c|c|c|c|c|c|}
\hline Pico & $\operatorname{tr} 1 D$ & $\operatorname{tr} 2 \mathrm{D}$ & Nome & Área (\%) & $S$ & Fórmula & PM & Classe \\
\hline 1 & 7,20 & 2,05 & Ácido propanoico & 5,62 & 832 & $\mathrm{C}_{3} \mathrm{H}_{6} \mathrm{O}_{2}$ & 74 & Ácido \\
\hline 17 & 11,20 & 3,23 & Furfural & 5,61 & 921 & $\mathrm{C}_{5} \mathrm{H}_{4} \mathrm{O}_{2}$ & 96 & Aldeído \\
\hline 18 & 11,20 & 3,44 & Ciclopentenona & 1,61 & 914 & $\mathrm{C}_{5} \mathrm{H}_{6} \mathrm{O}$ & 82 & Cetona \\
\hline 20 & 11,50 & 3,33 & Ciclopentenona & 1,27 & 920 & $\mathrm{C}_{5} \mathrm{H}_{6} \mathrm{O}$ & 82 & Cetona \\
\hline 25 & 12,80 & 2,79 & Álcool furfurílico & 3,82 & 952 & $\mathrm{C}_{5} \mathrm{H}_{6} \mathrm{O}_{2}$ & 98 & Álcool \\
\hline 34 & 15,40 & 3,15 & C1-Ciclopentenona & 1,70 & 927 & $\mathrm{C}_{6} \mathrm{H}_{6} \mathrm{O}$ & 96 & Cetona \\
\hline 36 & 15,50 & 3,21 & Furanil etanona & 1,58 & 916 & $\mathrm{C}_{6} \mathrm{H}_{6} \mathrm{O}_{2}$ & 110 & Cetona \\
\hline 39 & 15,80 & 4,76 & Ácido hidróxi butanoico & 1,88 & 939 & $\mathrm{C}_{4} \mathrm{H}_{8} \mathrm{O}_{3}$ & 104 & Ácido \\
\hline 40 & 15,80 & 5,41 & Dihidro furanona & 2,04 & 905 & $\mathrm{C}_{4} \mathrm{H}_{6} \mathrm{O}_{2}$ & 86 & Cetona \\
\hline 43 & 15,90 & 4,88 & Furanona & 4,49 & 946 & $\mathrm{C}_{4} \mathrm{H}_{4} \mathrm{O}_{2}$ & 84 & Cetona \\
\hline 58 & 18,60 & 4,01 & C1-Furfural & 1,11 & 916 & $\mathrm{C}_{6} \mathrm{H}_{6} \mathrm{O}_{2}$ & 110 & Aldeído \\
\hline 59 & 18,70 & 3,33 & C1-Furfural & 2,50 & 914 & $\mathrm{C}_{6} \mathrm{H}_{6} \mathrm{O}_{2}$ & 110 & Aldeído \\
\hline 60 & 18,70 & 3,53 & C1-Ciclopentenona & 1,43 & 954 & $\mathrm{C}_{6} \mathrm{H}_{8} \mathrm{O}$ & 110 & Cetona \\
\hline 63 & 18,80 & 3,03 & Pentanediona & 1,00 & 851 & $\mathrm{C}_{5} \mathrm{H}_{8} \mathrm{O}_{2}$ & 100 & Cetona \\
\hline 71 & 19,90 & 2,79 & Fenol & 1,67 & 943 & $\mathrm{C}_{6} \mathrm{H}_{6} \mathrm{O}$ & 94 & Fenol \\
\hline 73 & 20,30 & 4,59 & Hidróxi dihidro-furanona & 1,42 & 835 & $\mathrm{C}_{4} \mathrm{H}_{6} \mathrm{O}_{3}$ & 102 & Cetona \\
\hline 85 & 22,30 & 3,29 & C1-Ciclopentanediona & 1,69 & 937 & $\mathrm{C}_{6} \mathrm{H}_{8} \mathrm{O}_{2}$ & 112 & Cetona \\
\hline 106 & 25,50 & 4,84 & C1-Pirrolidinadiona & 2,47 & 956 & $\mathrm{C}_{5} \mathrm{H}_{7} \mathrm{NO}_{2}$ & 113 & Nitrogenado \\
\hline 108 & 25,60 & 4,80 & Pentanal & 4,18 & 778 & $\mathrm{C}_{5} \mathrm{H}_{10} \mathrm{O}$ & 86 & Aldeído \\
\hline 136 & 30,40 & 3,08 & C2-Metóxi-fenol & 1,69 & 761 & $\mathrm{C}_{8} \mathrm{H}_{10} \mathrm{O}_{2}$ & 138 & Fenol \\
\hline 137 & 30,70 & 3,06 & Ácido benzoico & 7,05 & 919 & $\mathrm{C}_{7} \mathrm{H}_{6} \mathrm{O}_{2}$ & 122 & Ácido \\
\hline 140 & 30,90 & 4,96 & C1-Hidróxi dihidro furanona & 1,92 & 945 & $\mathrm{C}_{5} \mathrm{H}_{8} \mathrm{O}_{3}$ & 116 & Cetona \\
\hline 144 & 31,50 & 3,12 & Benzenodiol (Resorcinol) & 2,74 & 908 & $\mathrm{C}_{6} \mathrm{H}_{6} \mathrm{O}_{2}$ & 110 & Fenol \\
\hline 145 & 31,60 & 4,31 & $\begin{array}{l}\text { Dianidro-glucopiranose } \\
\text { (Levoglucosano) }\end{array}$ & 3,24 & 904 & $\mathrm{C}_{6} \mathrm{H}_{8} \mathrm{O}_{4}$ & 144 & Açúcar \\
\hline 148 & 32,70 & 4,23 & C1-Hidróxi-furfural & 2,92 & 860 & $\mathrm{C}_{5} \mathrm{H}_{6} \mathrm{O}_{3}$ & 126 & Aldeído \\
\hline 156 & 35,40 & 3,55 & Benzenodiol (Hidroquinona) & 1,94 & 858 & $\mathrm{C}_{6} \mathrm{H}_{6} \mathrm{O}_{2}$ & 110 & Fenol \\
\hline
\end{tabular}

$\operatorname{tr} 1 D=$ tempo de retenção na primeira dimensão; $\operatorname{tr} 2 \mathrm{D}=$ tempo de retenção na segunda dimensão; $\mathrm{S}=$ similaridade; $\mathrm{PM}=$ peso molecular. 
GC $\times$ GC/TOFMS. Cada ponto preto nessa figura representa um pico cromatográfico detectado, não indicando, necessariamente, que o mesmo tenha sido positivamente identificado. Foram tentativamente identificados (apenas com o uso da biblioteca do equipamento e comparação com espectros de massas) 167 compostos, sendo que, de forma semiquantitativa, pôde-se compor a Tabela 2, onde são apresentados os 26 compostos majoritários (acima de 1\%) do bio-óleo, levando-se em consideração as áreas desses compostos. A identificação, por ser apenas uma tentativa,

Tabela 3 Distribuição das classes de compostos identificadas no bio-óleo de bagaço de laranja.

\begin{tabular}{lrrr}
\hline \multicolumn{1}{c}{$\begin{array}{c}\text { Classes de compostos } \\
\text { identificados }\end{array}$} & NP & NP\% & A\% \\
\hline Ácidos totais & 17 & 10,18 & 17,27 \\
Açúcares totais & 10 & 5,99 & 5,39 \\
Álcoois totais & 8 & 4,79 & 5,60 \\
Aldeídos totais & 7 & 4,19 & 16,47 \\
$\quad$ Derivados do furfural & 6 & 3,59 & 12,29 \\
Cetonas totais & 69 & 41,32 & 34,57 \\
Derivados da piranona & 3 & 1,80 & 1,83 \\
Derivados da furanona & 15 & 8,98 & 14,04 \\
Cetonas 6 cíclicas saturadas & 3 & 1,80 & 0,14 \\
Cetonas 6 cíclicas insaturadas & 4 & 2,40 & 0,79 \\
Cetonas 5 cíclicas saturadas & 4 & 2,40 & 2,87 \\
Cetonas 5 cíclicas insaturadas & 15 & 8,98 & 8,39 \\
Cetonas cíclicas totais & 26 & 15,57 & 28,05 \\
Ésteres totais & 4 & 2,40 & 1,39 \\
Éteres totais & 2 & 1,20 & 0,11 \\
Fenóis totais & 21 & 12,57 & 12,08 \\
Alquil fenóis & 8 & 4,79 & 2,86 \\
Metóxi fenóis & 5 & 2,99 & 3,18 \\
Benzenodióis & 8 & 4,79 & 6,04 \\
Nitrogenados totais & 28 & 16,77 & 7,11 \\
Derivados do pirrol & 6 & 3,59 & 2,93 \\
Derivados da piridina & 13 & 7,78 & 3,02 \\
\hline N & & & \\
\hline & & &
\end{tabular}

$\mathrm{N}=$ número de picos; $\mathrm{N} \%=$ percentual relativo ao número de picos (compostos em cada classe); \% = área percentual de cada composto em cada classe.

identifica os substituintes nas cadeias insaturadas e nos ciclos apenas pelo número de carbonos (ex.: $\mathrm{C}_{2}$ pode indicar uma etila ou duas metilas) sem posicioná-los. A identificação detalhada só pode ser realizada com padrões e/ou com o auxílio de índices de retenção, que não foram usados neste trabalho por ele ser ainda preliminar e ter como objetivo otimizar a análise e indicar as classes químicas predominantes no bio-óleo.

A Tabela 3, usando esse critério semiquantitativo, apresenta as diferentes classes de compostos identificados e a relação entre as áreas percentuais e o número de compostos presentes em cada classe.

Foram detectados compostos pertencentes a 9 classes distintas: ácidos, derivados de açúcares, aldeídos, álcoois, ésteres, éteres, cetonas, fenóis e compostos nitrogenados. Percebe-se que<smiles>[R]C1([R])C=CCCC1=O</smiles><smiles>[R]C1(C)CCCCC1=O</smiles>

Ciclopentenona Ciclopentanona<smiles>[R]C1C=CCOC1=O</smiles>

Furanona<smiles>[R]C1CC=CCC1=O</smiles>

Ciclohexenona<smiles>[R]C1(O)C=COC=C1</smiles>

Piranona<smiles>[R]C1CCCOC1=O</smiles><smiles>[R]C1CCCCC1=O</smiles><smiles>[R]C1(O)C=COCC1</smiles>

Dihidro furanona

Ciclohexanona Ciclohexenodiona

Dihidro piranona

Figura 4 Estruturas das principais cetonas identificadas no bio-óleo de bagaço de laranja, analisadas por $\mathrm{GC} \times \mathrm{GC} / \mathrm{TOFMS}$. 
ocorre uma boa separação, indicando inclusive a possibilidade de classificação dos compostos no espaço bidimensional. Os quatro compostos majoritários são ácidos carboxílicos (ácido benzoico - 7,05\% - e ácido propanoico - 5,6\%), seguidos de dois aldeídos (furfural - 5,61\% - e pentanal - 4,18\%) e uma cetona (furanona 4,49\%). Esses compostos estão assinalados em negrito na Tabela 2 .

As cetonas são a classe predominante $(69 \%$ dos picos e $34,6 \%$ da área), com destaque para as cetonas cíclicas, incluindo as derivadas do pirano e do furano. As estruturas das principais cetonas identificadas estão apresentadas na Figura 4.

Os compostos nitrogenados, por sua vez, apesar de apresentarem um número expressivo de compostos (28, correspondendo a $17 \%$ dos picos identificados) apresentam-se em concentrações baixas, representando apenas 7\% da área total identificada.
Uma das grandes vantagens analíticas da GC $\times$ GC é sua maior capacidade de pico, bem como o aumento de seletividade, devido à presença de uma segunda dimensão ( $\left.{ }^{2} \mathrm{D}\right)$, cujo mecanismo de separação difere daquele da primeira dimensão ( $\left.{ }^{1} \mathrm{D}\right)$. No caso do bio-óleo de bagaço de laranja foi possível verificar a presença de vários analitos, cujos ${ }^{1} t_{R}$ são semelhantes $\mathrm{e}$ poderiam resultar em coeluições na 1D-GC. Através do emprego da GC×GC o número de coeluições diminui consideravelmente, visto que vários componentes são resolvidos cromatograficamente na ${ }^{2} \mathrm{D}$.

A Figura 5 ilustra a separação da cetona hidróxi butanona $\left({ }^{2} t_{R}=2,52\right.$ segundos) e do composto nitrogenado C1-tetrazol $\left({ }^{2} t_{R}=3,15\right.$ segundos) na ${ }^{2} \mathrm{D}$, cujo tempo de retenção na ${ }^{1} \mathrm{D}$ é de 8,40 minutos. Os espectros de massas destes compostos também são apresentados na Figura 5, onde se verifica a

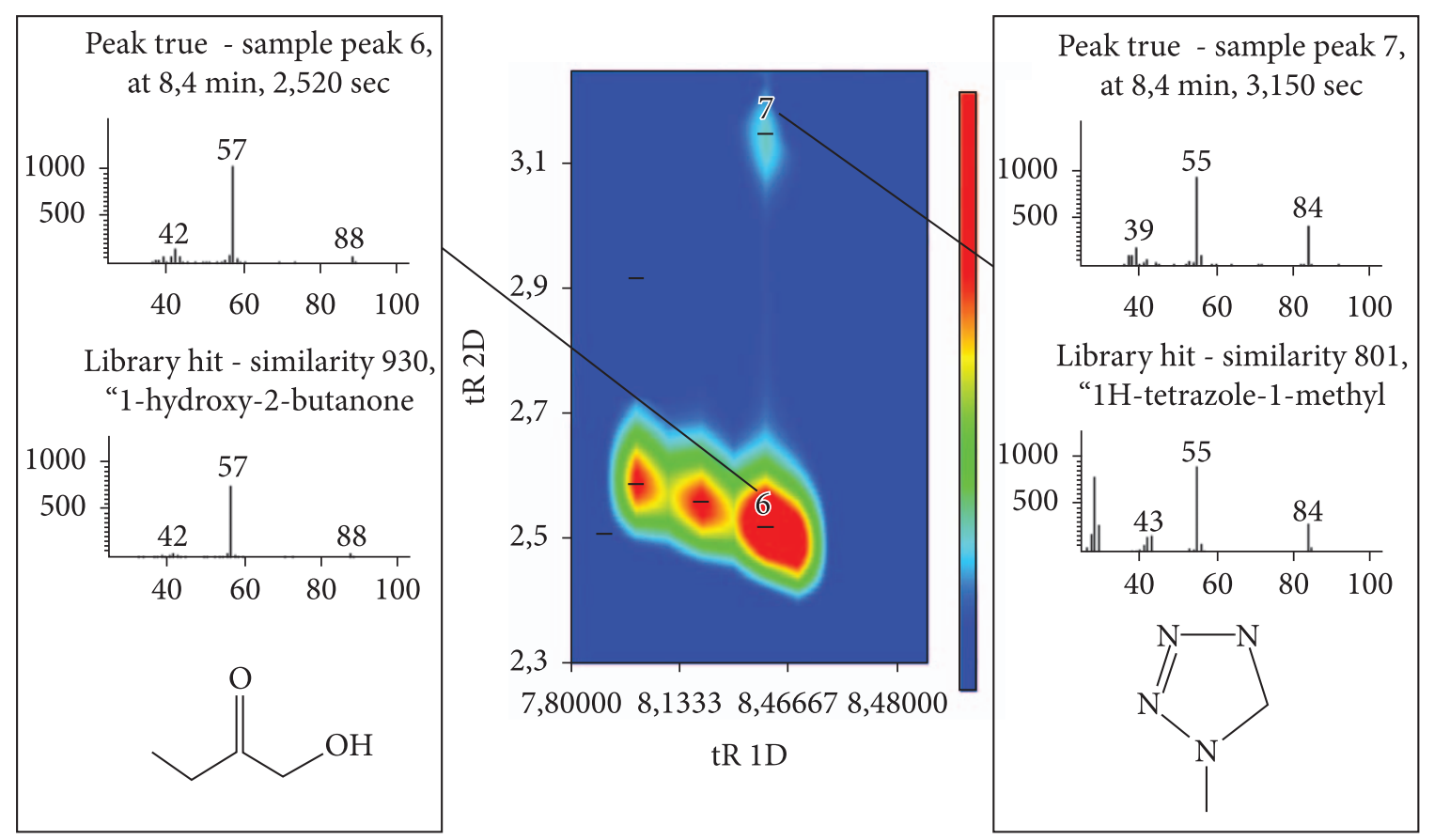

Figura 5 Exemplo de separação na segunda dimensão para dois compostos que apresentam o mesmo tempo de retenção na primeira dimensão e tempos de retenção distintos na segunda dimensão: ${ }^{1} t_{R}=8,40$ minutos; ${ }^{2} t_{R}=2,52$ segundos para a hidróxi butanona e ${ }^{2} t_{R}=3,15$ segundos para o metil tetrazol. 
fragmentação distinta para as duas estruturas. Entretanto, em alguns casos, a maior seletividade da $\mathrm{GC} \times \mathrm{GC}$, conferida por duas colunas portadoras de fases estacionárias diferentes, não é suficiente para separação de certos com- postos que coeluem em ambas as dimensões. Nessas situações, o emprego do TOFMS permite o uso do software de deconvolução, o qual consiste basicamente na resolução de dois ou mais compostos minimamente separados atra-

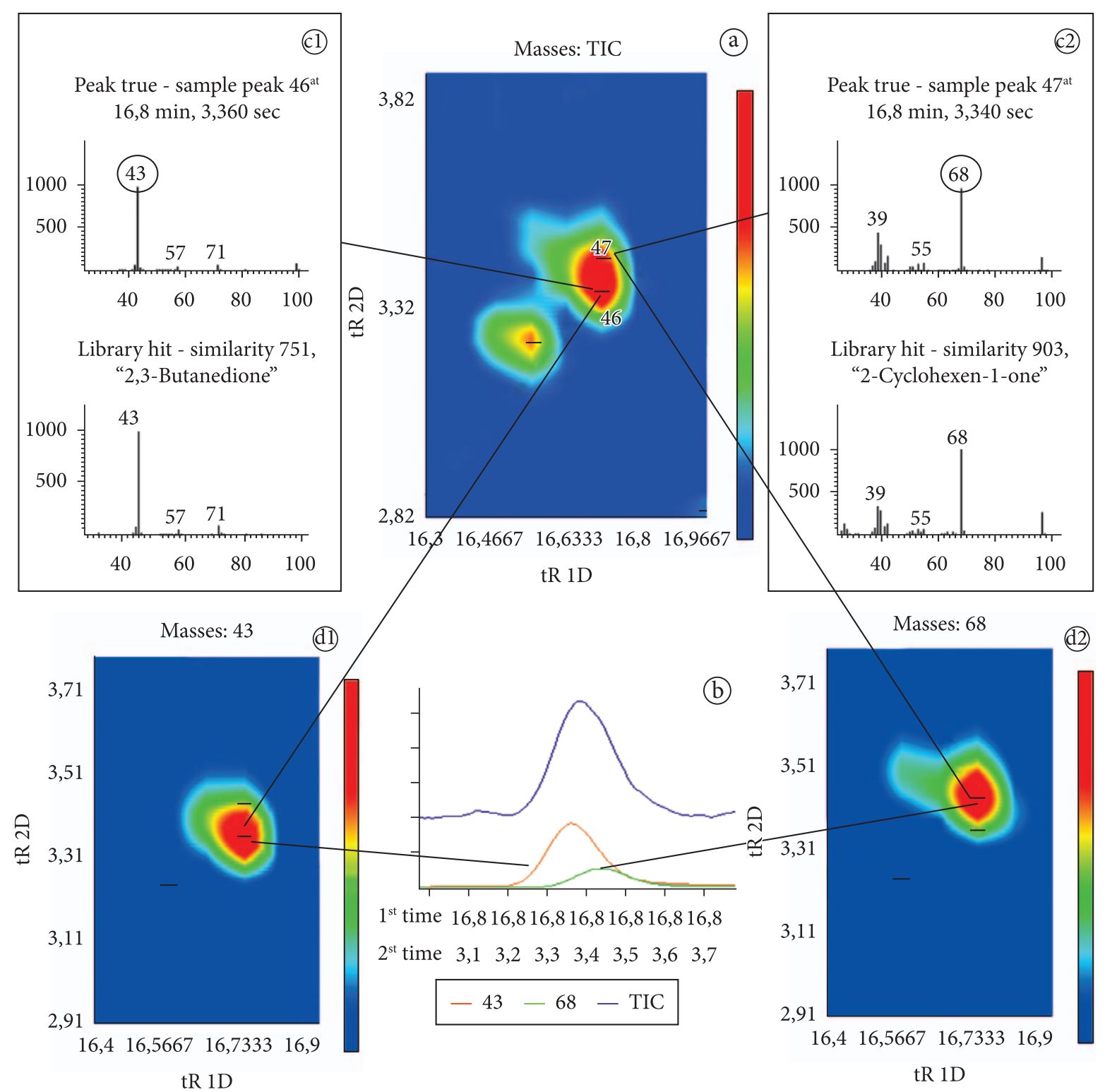

Figura 6 Exemplo de deconvolução espectral para dois componentes que coeluem na ' $D\left({ }^{1} t_{R}=16,80\right.$ minutos) e também na ${ }^{2} \mathrm{D}$ na amostra de bio-óleo de bagaço de laranja: ${ }^{2} t_{R}$ da 2,3-butanediona (pico 46) = 3,36 segundos; ${ }^{2} t_{R}$ da 2-ciclohexen-1-ona (pico 47)= 3,44 segundos; a) Ampliação de uma parte do diagrama de cores para melhor visualização dos compostos 46 e 46; b) Cromatograma na segunda dimensão reconstruído a partir da corrente iônica total (linha azul) das correntes iônicas deconvoluídas para valores selecionados (traço verde para o íon 68 e traço laranja para o íon 43); c1 e c2) Espectros de massas dos componentes da amostra e os respectivos espectros de massas encontrados na biblioteca NIST para cada composto e; d1 e d2) Diagramas de cores com íons selecionados mostrando a deconvolução dos picos. 
vés das diferenças existentes em seus espectros de massas. O TOFMS apresenta a vantagem de produzir espectros onde a totalidade dos íons é coletada ao mesmo tempo, garantindo que todas as razões dos íons sejam semelhantes ao longo do pico cromatográfico. Esta continuidade espectral assegura um processo de deconvolução bem-sucedido, onde um espectro de massas de qualidade é obtido mesmo quando a separação cromatográfica não é eficiente. Os requisitos para uma deconvolução espectral apropriada são: uma pequena diferença entre os ápices dos picos coeluídos e dessemelhança suficiente entre os espectros de massas dos compostos mal separados ${ }^{[36]}$.

A Figura 6 mostra um exemplo típico de deconvolução para dois compostos do bio-óleo de laranja: butanediona (pico 46) $\left({ }^{2} t_{R}=3,36\right.$ segundos) e ciclohexenona (pico 47) $\left({ }^{2} t_{\mathrm{R}}=3,44\right.$ segundos $)$, ambos eluindo em 16,80 minutos na primeira dimensão. A fragmentação que se observa no espectro de massas dos dois compostos é bastante diferente e, portanto, a reconstrução do cromatograma na segunda dimensão através das correntes iônicas deconvoluídas (DIC, do inglês, deconvoluted ion current) pode ser empregada para resolver problemas de separação cromatográfica no âmbito da espectrometria de massas (Figura 6). No caso do exemplo da Figura 6a, foi escolhido um íon característico para cada composto: $\mathrm{m} / \mathrm{z}$ 43 para a butanediona e $m / z 68$ para a ciclohexenona, gerando o cromatograma reconstruído da Figura 6b. Observa-se que foi possível separar os dois componentes coeluídos por deconvolução espectral, de forma que se obteve os espectros de massas semelhantes aos destes compostos na biblioteca NIST com similaridades de 751 e 903 para butanediona e ciclohexenona, respectivamente.

\section{Conclusões}

A seletividade superior da cromatografia gasosa bidimensional abrangente foi demonstrada através da separação de compostos do bio-óleo de bagaço de laranja que coeluíram na primeira dimensão, de caráter apolar, tendo sido separados na fase estacionária da segunda dimensão, de maior polaridade. $\mathrm{O}$ uso da deconvolução espectral como vantagem analítica da GC $\times$ GC/TOFMS também foi demonstrado para separação de componentes que eluíram simultaneamente nas duas dimensões cromatográficas, evidenciando a capacidade de separação dessas duas técnicas. Além disso, o bio-óleo de bagaço de laranja foi analisado pela primeira vez por GC $\times$ GC/TOFMS, tendo-se apresentado a otimização de alguns parâmetros analíticos dessa análise. Cento e sessenta e sete compostos do bio-óleo em estudo foram tentativamente identificados, dentre os quais destacam-se ácidos, aldeídos, álcoois, cetonas, fenóis, éteres, ésteres e compostos nitrogenados. Vinte e seis compostos puderam ser claramente identificados como majoritários, usando-se a comparação direta das áreas sob os picos cromatográficos. Destacaram-se o ácido benzoico $(7,05 \%)$, o furfural (5,61\%), o ácido propanoico (5,6\%), a furanona $(4,49 \%)$ e o pentanal $(4,18 \%)$. Alguns desses compostos podem ser empregados para fabricação de produtos de maior valor agregado, à medida que as condições de pirólise são direcionadas para a produção majoritária daqueles que forem mais promissores para a indústria.

\section{Agradecimentos}

Ao prof. dr. Ayrton Figueiredo Martins e ao dr. André de Lima Cardoso, da Universidade Federal de Santa Maria, pelo fornecimento das amostras de bio-óleo, e à FINEP e ao CNPq, pelo apoio financeiro, na forma de bolsas de apoio a projetos. 


\section{Referências}

1 Goldemberg J. Biomassa e energia. Química Nova 2009; 32(3):582-587.

2 Galembeck F, Barbosa CAS, Sousa RA. Aproveitamento sustentável de biomassa e de recursos naturais na inovação química. Química Nova 2009; 32:572-581. http://dx.doi.org/10.1590/S0100-40422009000300003

3 Instituto Brasileiro de Geografia e Estatística - IBGE. [cited 2010 ago.]. Available from: http://www.ibge.gov.br.

4 Cortez LAB, Lora ES. Biomassa para energia. Campinas: Editora da Unicamp; 2006.

5 Centro de Tecnologia Canavieira - CTC. [cited 2010 ago.]. Available from: http://ctcanavieira.com.br.

6 Ripoli TCC, Ripoli MLC. Biomassa de cana-de-açúcar: colheita, energia e ambiente. Piracicaba; 2004.

7 Ripoli MLC, Gamero CA. Palhiço de Cana-deaçúcar: Ensaio Padronizado de recolhimento por enfardamento cilíndrico. Revista Energia na Agricultura 2007; 22(1):75-93.

8 Michelazzo MB, Braunbeck OA. Análise de seis sistemas de recolhimento do palhiço na colheita mecânica da cana-de-açúcar. Revista Brasileira de Engenharia Agrícola e Ambiental 2008; 12(5): 546-552.

9 Brás AM, Miranda F, Hipólito L, Dias LS. Biomassa e produção de energia. Revista $O$ Minho, a Terra e o Homem 2006; 51:23-30.

10 Barbosa LCA, Silvério FO, Veloso DP. Determinação da relação siringila/guaiacila da lignina em madeiras de eucalipto por pirólise acoplada à cromatografia gasosa e espectrometria de massas (PI - CG/EM). Química Nova 2008; 31(8):2035-2041. http://dx.doi. org/10.1590/S0100-40422008000800023

11 Cardoso AL. Biorrefinaria: Investiga Investigação de Processos Fisico-Quimico, Fermentativo e Térmico de Aproveitamento de Serragem de Eucalipto [tese]. Santa Maria: Universidade Federal de Santa Maria; 2009.

12 Bridgwater AV, Czernik S. Overview of Applications of Biomass Fast Pyrolysis Oil. Energy Fuels 2004; 18(2):590-598. http://dx.doi.org/10.1021/ ef034067u

13 Couto GM. Utilização da serragem de Eucalyptus sp. na preparação de carvões ativados [dissertação]. Lavras: Universidade Federal de Lavras, 2009.

14 Cortez LAB, Rocha JD, PérezJMM.Energia na Indústria de Açúcar e Álcool. UNIFEI, UNICAMP; 2004. p 1-22.

15 Santos F, Curvelo AAS. Polímeros. São Paulo: Universidade de São Paulo; 1999.

16 Mesa JM, Rocha JD, Olivares E, Barboza LA, Brossard LE, Brossard Junior, LEB. Pirólise Rápida em Leito
Fluidizado: Uma Opção para transformar Biomassa em Energia Limpa. Revista Analytica 2003; 4:32-36.

17 Brasil. Ministério de Minas e Energia. [cited 2010 out.]. Available from: http://www.mme.gov.br/mme.

18 Diniz J. Conversão termica de casca de arroz a baixa temperatura: producao de biooleo e residuo silico-carbonoso adsorvente [tese]. Santa Maria: Universidade Federal de Santa Maria; 2005.

19 Samaniedo MRP. Uso de biocombustivel da pirolise rapida da palha de cana em um motor de ciclo Otto [dissertação]. Campinas: Universidade Estadual de Campinas; 2007.

20 Yaman S. Pyrolysis of biomass to produce fuels and chemical feedstocks. Energy Conversion and Management 2004; 45(5):651-671. http://dx.doi. org/10.1016/S0196-8904(03)00177-8

21 Arni SA, Bosio B, Arato E. Syngas from sugarcane pyrolysis: An experimental study for fuel cell applications. Renewable Energy 2010; 35(1):29-35. http://dx.doi.org/10.1016/j.renene.2009.07.005

22 Lee MK, Tsai WT, Tsai YL, Lin SH. Pyrolysis of napier grass in an induction-heating reactor. Journal of Analytical and Applied Pyrolysis 2010; 88(2):110-116. http://dx.doi.org/10.1016/j.jaap.2010.03.003

23 Strezov V, Evans TJ, Hayman C. Thermal conversion of elephant grass (Pennisetum Purpureum Schum) to bio-gas, bio-oil and charcoal. Bioresource Technology 2008; 99(17):8394-8399. PMid:18406608. http://dx.doi.org/10.1016/j.biortech.2008.02.039

24 Nowakowski DJ, Jones JM. Uncatalysed and potassiumcatalysed pyrolysis of the cell-wall constituents of biomass and their model compounds. Journal of Analytical and Applied Pyrolysis 2008; 83(1):12-25. http://dx.doi.org/10.1016/j.jaap.2008.05.007

25 Von Mühlen C, Zini CA, Caramão EB, Marriott PJ. Caracterização de amostras petroquímicas e derivados utilizando cromatografia gasosa bidimensional abrangente (GCxGC). Química Nova 2006; 29(4):765-775. http://dx.doi.org/10.1590/ S0100-40422006000400025

26 Von Mühlen C, Zini CA, Caramão EB, Marriott PJ. Nomenclatura na língua portuguesa em cromatografia multidimensional abrangente. Química Nova 2007; 30(3):682-687. http://dx.doi.org/10.1590/ S0100-40422007000300030

27 Dallüge J, Beens J, Brinkman UA. Comprehensive two-dimensional gas chromatography: a powerful and versatile analytical tool. Journal of Chromatography A 2003; 1000(1-2):69-108. http://dx.doi.org/10.1016/ S0021-9673(03)00242-5 
28 Zini CA. Cromatografia Gasosa Bidimensional. Scientia Chromatographica 2009; 1:31.

29 Cortes HJ, Winniford B, Luong J, Pursch M. Comprehensive two dimensional gas chromatography review. Journal of Separation Science 2009; 32(56):883-904. PMid:19278007. http://dx.doi. org/10.1002/jssc.200800654

30 Mondello L, Tranchida PQ, Dugo P, Dugo G. Comprehensive two-dimensional gas chromatography-mass spectrometry: A review. Mass Spectrometry Reviews 2008; 27(2):101-124. PMid:18240151. http://dx.doi.org/10.1002/mas.20158

31 Giese EC, Dekker RFH, Barbosa AM. Orange bagasse as substrate for the production of pectinase and laccase by Botryosphaeria rhodina MAMB-05 in submerged and solid state fermentation. Bioresources 2008; 3(2):335-345.

32 Martins AF, Diniz J, Stahl JA, Cardoso AL. Caracterização dos produtos líquidos e do carvão da pirólise de serragem de eucalipto. Química Nova 2007; 30(4):873-878. http://dx.doi.org/10.1590/ S0100-40422007000400021
33 Martins AF, Cardoso AL, Stahl JA, Diniz J. Low temperature conversion of rice husks, eucalyptus sawdust and peach stones for the production of carbon-like adsorbent. Bioresource Technol. 2007; 98(5):1095-1100. PMid:16790341. http://dx.doi.org/10.1016/j.biortech.2006.04.024

34 Marsman JH, Wildschut J, Mahfud F, Heeres HJ. Identification of components in fast pyrolysis oil and upgraded products by comprehensive two-dimensional gas chromatography and flame ionisation detection. Journal of Chromatography A 2007; 1150(1-2):21-27. PMid:17141251. http:// dx.doi.org/10.1016/j.chroma.2006.11.047

35 Ramos L. Comprehensive Two Dimensional Gas Chromatography. Amsterdam: Elsevier; 2009. vol. 55.

36 Focant J-F, Cochran JW, Dimandja J-M, DePauw E, Sjödin A, Turner WE et al. High-throughput analysis of human serum for selected polychlorinated biphenyls (PCBs) by gas chromatography-isotope dilution time-of-flight mass spectrometry (GC-IDTOFMS). Analyst 2004; 129:331-336. PMid:15042164. http:// dx.doi.org/10.1039/b313675b 